\title{
Symptomatic severe acute respiratory syndrome coronavirus 2 reinfection in a lupus patient treated with hydroxychloroquine: a case report
}

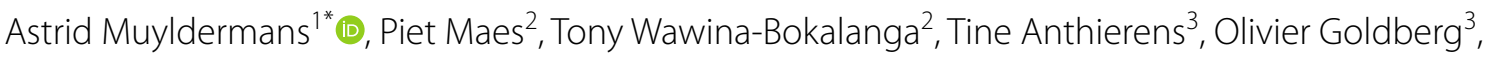 \\ Magali Bartiaux ${ }^{4}$, Oriane Soetens ${ }^{1}$, Ingrid Wybo ${ }^{1}$, Sigi Van den Wijngaert ${ }^{5}$ and Denis Piérard ${ }^{1}$
}

\begin{abstract}
Background: Hydroxychloroquine and chloroquine have been used for hospitalized coronavirus disease 2019 patients because of their antiviral and anti-inflammatory function. However, little research has been published on the impact of the immunomodulatory effect of (hydroxy)chloroquine on humoral immunity.

Case presentation: We report a case of symptomatic severe acute respiratory syndrome coronavirus 2 reinfection, diagnosed 141 days after the first episode, in a 56-year-old man of Black African origin treated with hydroxychloroquine for lupus erythematosus. No anti-severe acute respiratory syndrome coronavirus $2 \mathrm{lgG}$ antibodies could be detected 127 days after the initial episode of coronavirus disease 2019.

Conclusions: The treatment with hydroxychloroquine probably explains the decreased immune response with negative serology and subsequent reinfection in our patient. As humoral immunity is crucial to fight a severe acute respiratory syndrome coronavirus 2 infection, the use of (hydroxy)chloroquine is likely to have a detrimental effect on the spread of the virus. This case emphasizes that more needs to be learned about the role of antibodies in protecting against severe acute respiratory syndrome coronavirus 2 (re)infection and the role of (hydroxy)chloroquine on humoral immunity.
\end{abstract}

Keywords: SARS-CoV-2, COVID-19, Reinfection, Hydroxychloroquine, Lupus, Case report

\section{Background}

(Hydroxy)chloroquine has been used for decades as prophylaxis and treatment of malaria and autoimmune diseases such as lupus erythematosus. In March 2020, the US Food and Drug Administration (FDA) allowed the use of hydroxychloroquine and chloroquine for certain hospitalized coronavirus disease 2019 (COVID-19) patients

\footnotetext{
*Correspondence: astrid.muyldermans@uzbrussel.be

${ }^{1}$ Department of Microbiology and Infection Control, Vrije Universiteit

Brussel (VUB), Universitair Ziekenhuis Brussel (UZ Brussel), Laarbeeklaan

101, 1090 Brussels, Belgium

Full list of author information is available at the end of the article
}

as an emergency use authorization (EUA). Possible beneficial effects may be attributed to its antiviral and antiinflammatory function $[1,2]$. In June 2020, this EUA was revoked as the known and potential benefits no longer outweighed the known and potential risks, including serious cardiac adverse events. However, little research has been published on the impact of the immunomodulatory effect of (hydroxy)chloroquine on humoral immunity $[1,3]$. original author(s) and the source, provide a link to the Creative Commons licence, and indicate if changes were made. The images or other third party material in this article are included in the article's Creative Commons licence, unless indicated otherwise in a credit line to the material. If material is not included in the article's Creative Commons licence and your intended use is not permitted by statutory regulation or exceeds the permitted use, you will need to obtain permission directly from the copyright holder. To view a copy of this licence, visit http://creativecommons.org/licenses/by/4.0/. The Creative Commons Public Domain Dedication waiver (http://creativeco mmons.org/publicdomain/zero/1.0/) applies to the data made available in this article, unless otherwise stated in a credit line to the data. 


\section{Case presentation}

On 9 April 2020, a 56-year-old obese man (BMI 35) of Black African origin with discoid lupus erythematosus (treated with hydroxychloroquine $200 \mathrm{mg}$ twice a day) presented at the emergency department (ED) of the Centre Hospitalier Universitaire Saint-Pierre (CHUSP) with dyspnea for 2 weeks, dry cough, chest pain, myalgia, headache, ageusia, and diarrhea. One week earlier he had returned from the Democratic Republic of Congo (DRC) where he resided for 2 months. Malaria prophylaxis (atovaquone/proguanil) was taken correctly. Upon admission, a nasopharyngeal swab was taken and severe acute respiratory syndrome coronavirus 2 (SARS-CoV-2) was detected by real-time reverse transcription polymerase chain reaction (RT-PCR) (RealStar ${ }^{\circledR}$ SARS-CoV-2 RT-PCR Kit 1.0, Altona Diagnostics GmbH, Hamburg, Germany; targeting E-gene and S-gene) with a crossing point $(\mathrm{Cp})$ of 36 , but no abnormalities were observed on a chest computed tomography (CT) (Fig. 1) and oxygen saturation was $100 \%$. His body temperature was $37.1{ }^{\circ} \mathrm{C}$ and the following laboratory parameters were within normal limits: C-reactive protein (CRP; $1.0 \mathrm{mg} / \mathrm{L}$ ), leukocytes $\left(4.3 \times 10^{3} / \mu \mathrm{L}\right)$, lymphocytes $\left(1.8 \times 10^{3} / \mu \mathrm{L}\right)$, neutrophils $\left(1.8 \times 10^{3} / \mu \mathrm{L}\right)$, platelets $\left(214 \times 10^{3} / \mu \mathrm{L}\right)$, and hemoglobin $(14.7 \mathrm{~g} / \mathrm{dL})$. The patient was placed in home quarantine for 2 weeks.

On 28 April he presented himself to Universitair Ziekenhuis Brussel's (UZB's) ED with chest pain, abdominal pain, and diarrhea for a week. The imaging was repeated, but again no abnormalities were observed on a chest CT (Fig. 1). However, cardiac troponin T was slightly elevated $(0.011 \mu \mathrm{g} / \mathrm{L})$, suggesting the diagnosis of pericarditis. Aspirin (1000 mg four times a day) was prescribed and the patient was discharged.

On 4 June, SARS-CoV-2 RT-PCR (RealStar ${ }^{\circledR}$ ) was performed prior to a planned 1-day hospitalization in UZB for gastroscopy because of postprandial bloating. This test was negative. No abnormalities were found by the gastroscopy, and the patient decided to discontinue hydroxychloroquine on his own initiative as gastrointestinal discomfort can be a side effect of the drug.

A serological analysis (LIAISON ${ }^{\circledR}$ SARS-CoV-2 S1/S2 IgG, Diasorin, Saluggia, Italy) performed 127 days after the initial episode (14 August) could not detect antiSARS-CoV-2 IgG antibodies against spike protein.

On 28 August (141 days after the initial episode), the patient presented at UZB's ED with dyspnea, productive cough, malaise, fever, dysosmia, and dysgeusia for 3 days. A nasopharyngeal swab was taken showing a strong positive result for SARS-CoV-2 (Cp 14) $\left(\operatorname{RealStar}^{\circledR}\right)$. Moreover, laboratory analysis showed a mild leukopenia $\left(3.2 \times 10^{3} / \mu \mathrm{L}\right)$ and lymphocytopenia $\left(0.9 \times 10^{3} / \mu \mathrm{L}\right)$, however CRP $(1.8 \mathrm{mg} / \mathrm{L})$, neutrophils $\left(1.6 \times 10^{3} / \mu \mathrm{L}\right)$, platelets $\left(168 \times 10^{3} / \mu \mathrm{L}\right)$, and hemoglobin $(13.2 \times \mathrm{g} / \mathrm{dL})$ were within normal limits. No abnormalities were observed on a bedside chest
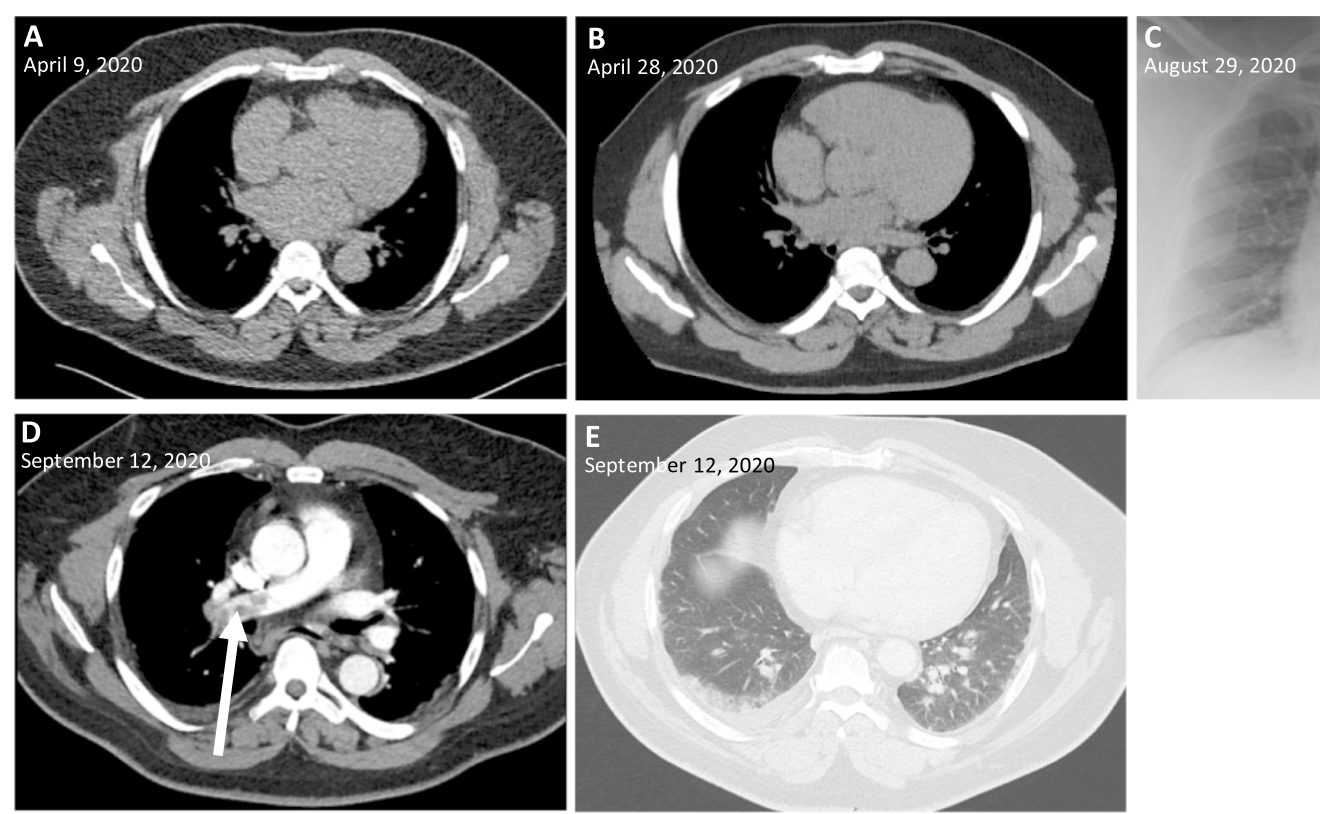

Fig. 1 Chest computed tomography and radiograph images during the disease course. A-B, chest computed tomography (CT) without abnormalities; $\mathbf{C}$ bedside chest radiograph without alveolar consolidations; D CT pulmonary angiogram showing pulmonary embolism (arrow); $\mathbf{E}$ chest CT showing peripheral ground-glass opacities and pleural effusion in the right lower lobe 
radiograph (Fig. 1). The patient was placed in home quarantine, but presented himself again 4 days later (1 September) because of persistent complaints with decreased oxygen saturation (93.9\%). He was hospitalized and oxygen therapy was started $(2 \mathrm{~L} / \mathrm{min})$. The oxygen could be stopped after 12 hours (oxygen saturation 99\%) and he stayed in the hospital for 1 week with symptomatic treatment. An evaluation for humoral immune deficiency was performed, however no general antibody deficiency was observed by measurement of serum immunoglobulin levels (IgG, IgA, IgM). Only 4 days after his hospital discharge, the patient presented at CHUSP's ED with dyspnea, productive cough, and chest pain. Laboratory results showed an elevation of D-dimer $(4183 \mathrm{ng} / \mathrm{mL})$ and CRP $32 \mathrm{mg} / \mathrm{L}$. The following parameters were within normal limits: leukocytes $\left(8.3 \times 10^{3} / \mu \mathrm{L}\right)$, lymphocytes $\left(1.9 \times 10^{3} / \mu \mathrm{L}\right)$, neutrophils $\left(5.4 \times 10^{3} / \mu \mathrm{L}\right)$, platelets $\left(314 \times 10^{3} / \mu \mathrm{L}\right)$, and hemoglobin $(13.0 \mathrm{~g} / \mathrm{dL})$. A CT pulmonary angiogram was performed showing pulmonary embolism and ground-glass opacities compatible with viral pneumonia (Fig. 1). Serological analysis performed 158 days after the first episode (14 September), showed the presence of anti-SARS-CoV-2 IgG antibodies to spike protein (130 AE/mL, Diasorin). Anticoagulation by tinzaparin sodium was initiated (followed by rivaroxaban after 14 days, $15 \mathrm{mg}$ twice a day), as well as empirical antibiotic therapy by ceftriaxone ( $2 \mathrm{~g}$ daily for 7 days). No antiviral therapy or supplemental oxygen was started. On 29 September he was discharged, 173 days after the initial episode.

Genome sequencing was performed on nasopharyngeal swabs from the first and second episode with a MinION (Oxford Nanopore Technologies, Oxford, United Kingdom) using the ARTIC network nCoV2019 sequencing protocols and analytic pipeline by Josh Quick [4]. From the sample of the initial episode, taken 2 weeks after the first symptoms, only a fragmented genome (6028 out of $29903 \mathrm{bps}$ ) could be determined, most likely due to a low viral load of the nasopharyngeal swab (Cp 36). A full-length sequence of the second episode could be determined, revealing a lineage B.1. SARS-CoV-2 [5].

Seven mutations were identified across the genome of the two strains (Table 1). Especially the key block mutation at positions 28881 to 28883 (AAC to GGG) in the nucleocapsid phosphoprotein region resulting in an amino acid change (lysine-arginine to arginineglycine), indicates that the patient suffered from a reinfection [6]. The coverage for this triplet region was 121 -fold for the first episode and 1586-fold for the second episode (with presence of the mutation in 100\% of the reads).
Table 1 Observed mutations between the genomes of the first and second episode

\begin{tabular}{lll}
\hline Position (bp) & Base change & Gene \\
\hline 241 & C to T & ORF1a \\
28831 & C to T & Nucleocapsid phosphoprotein \\
28854 & C to T & Nucleocapsid phosphoprotein \\
$28881-28883$ & AAC to GGG & Nucleocapsid phosphoprotein \\
29034 & A to C & Nucleocapsid phosphoprotein \\
\hline
\end{tabular}

\section{Discussion and conclusions}

The patient was likely initially infected in the DRC, which counted 134 confirmed cases in the beginning of April 2020, as he already had symptoms during his stay [7]. The viral load tested on his return to Belgium was low. The patient experienced only mild symptoms during this first episode. At that moment, the patient was treated with hydroxychloroquine because of lupus. Since the EUA from FDA for (hydroxy)chloroquine for hospitalized COVID-19 patients, an increasing number of studies have been published with conflicting results about its effectivity $[2,8,9]$. However, little research has been published on the impact of the immunomodulatory effect of (hydroxy)chloroquine on humoral immunity $[1,3]$. Chloroquine has been shown to suppress the antibody responses to vaccines against rabies, tetanus, and diphtheria [3]. This can be attributed to the fact that (hydroxy)chloroquine affects functions of proteins involved in antigen-presenting pathways and B-cell activation [3]. In a study of patients with Chikungunya virus infection, it was shown that the adaptive immune response was delayed due to chloroquine treatment in the acute phase [10]. So, hydroxychloroquine treatment may impair host immunity in response to SARS-CoV-2, however the effects on immune cell function have not been extensively examined [11]. As humoral immunity is crucial to fight a SARS-CoV-2 infection, the use of (hydroxy)chloroquine is likely to have a detrimental effect on the spread of the virus [1].

Our patient was treated with hydroxychloroquine for lupus, probably explaining the decreased immune response with negative serology (IgG) 127 days after the initial episode of COVID-19, and subsequent reinfection. At the time of reinfection, the use of hydroxychloroquine was discontinued and an IgG antibody response was detected 158 days after the initial episode. It has been shown that the IgG antibody response after a COVID-19 infection can wane with possible reinfection [12-14]. However, to conclude, our case emphasizes the need for trials about the role of COVID-19 
treatment in general, and (hydroxy)chloroquine in particular, on the (humoral) immunity response [3].

\begin{abstract}
Abbreviations
FDA: Food and Drug Administration; EUA: Emergency use authorization; ED: Emergency department; DRC: Democratic Republic of Congo; SARS-CoV-2: Severe acute respiratory syndrome coronavirus 2; RT-PCR: Reverse transcription polymerase chain reaction; $\mathrm{Cp}$ : Crossing point; CT: Computed tomography; COVID-19: Coronavirus disease 2019
\end{abstract}

\section{Acknowledgements}

Not applicable.

\section{Authors' contributions}

AM: interpretation of laboratory results and writing of the manuscript. OS, IW, SVDW, DP: interpretation of laboratory results. PM and TWB: analysis and interpretation of genome sequencing. TA, OG, MB: clinical care of patient. All authors read and approved the final manuscript.

\section{Funding}

The authors did not receive support from any organization for the submitted work.

\section{Availability of data and materials}

All data generated or analysed during this study are included in this published article.

\section{Declarations}

\section{Ethics approval and consent to participate}

Ethical approval was obtained from the Medical Ethics Committee UZ Brussel VUB (B.U.N. 1432020000310). Written informed consent was obtained from the patient included in the study.

\section{Consent for publication}

Written informed consent was obtained from the patient for publication of this case report and any accompanying images. A copy of the written consent is available for review by the Editor-in-Chief of this journal.

\section{Competing interests}

The authors declare that they have no competing interests.

\section{Author details}

${ }^{1}$ Department of Microbiology and Infection Control, Vrije Universiteit Brussel (VUB), Universitair Ziekenhuis Brussel (UZ Brussel), Laarbeeklaan 101, 1090 Brussels, Belgium. ${ }^{2}$ Department of Microbiology, Immunology and Transplantation, Laboratory of Clinical and Epidemiological Virology, KU Leuven, Rega Institute for Medical Research, Leuven, Belgium. ${ }^{3}$ Department of Emergency Medicine, Vrije Universiteit Brussel (VUB), Universitair Ziekenhuis Brussel (UZ Brussel), Brussels, Belgium. ${ }^{4}$ Department of Emergency Medicine, Centre Hospitalier Universitaire Saint-Pierre (CHUSP), Brussels, Belgium. ${ }^{5}$ Department of Microbiology, Laboratoire Hospitalier Universitaire Bruxelles-Universitair Laboratorium Brussel (LHUB-ULB), Brussels, Belgium.

Received: 13 January 2021 Accepted: 19 October 2021

Published online: 26 November 2021

\section{References}

1. Li X, Wang Y, Agostinis P, Rabson A, Melino G, Carafoli E, et al. Is hydroxychloroquine beneficial for COVID-19 patients? Cell Death Dis. 2020;11(7):512.

2. Geleris J, Sun Y, Platt J, Zucker J, Baldwin M, Hripcsak G, et al. Observational study of hydroxychloroquine in hospitalized patients with Covid19. N Engl J Med. 2020;382(25):2411-8.
3. de Miranda Santos IKF, Costa CHN. Impact of hydroxychloroquine on antibody responses to the SARS-CoV-2 Coronavirus. Front Immunol. 2020:11:1739.

4. Protocols.io. nCoV-2019 sequencing protocol. https://www.protocols.io/ view/ncov-2019-sequencing-protocol-v3-locost-bh42j8ye. Accessed 15 Oct 2020.

5. Rambaut A, Holmes EC, O'Toole Á, Hill V, McCrone JT, Ruis C, et al. A dynamic nomenclature proposal for SARS-CoV-2 lineages to assist genomic epidemiology. Nat Microbiol. 2020;5(11):1403-7.

6. Nextstrain. Genomic epidemiology of novel coronavirus - global subsampling. https://nextstrain.org/ncov/global. Accessed 15 Oct 2020.

7. World Health Organization. Coronavirus disease 2019 (COVID-19) Situation Report-74. https://www.who.int/docs/default-source/coronaviru se/situation-reports/20200403-sitrep-74-covid-19-mp.pdf?sfvrsn=4e043 d03_14. Accessed 1 Sept 2020.

8. Lammers AJJ, Brohet RM, Theunissen REP, Koster C, Rood R, Verhagen DWM, et al. Early hydroxychloroquine but not chloroquine use reduces ICU admission in COVID-19 patients. Int J Infect Dis. 2020;101:283-9.

9. Horby P, Mafham M, Linsell L, Bell JL, Staplin N, Emberson JR, et al. Effect of hydroxychloroquine in hospitalized patients with Covid-19. N Engl J Med. 2020;383(21):2030-40.

10. Roques $P$, Thiberville SD, Dupuis-Maguiraga L, Lum FM, Labadie K, Martinon $F$, et al. Paradoxical effect of chloroquine treatment in enhancing chikungunya virus infection. Viruses. 2018;10(5):268.

11. Devarajan A, Vaseghi M. Hydroxychloroquine can potentially interfere with immune function in COVID-19 patients: mechanisms and insights. Redox Biol. 2021:38:101810.

12. To KK, Hung IF, Ip JD, Chu AW, Chan WM, Tam AR, et al. COVID-19 re-infection by a phylogenetically distinct SARS-coronavirus-2 strain confirmed by whole genome sequencing. Clin Infect Dis. 2020. https://doi.org/10. 1093/cid/ciaa1275.

13. To KK, Hung IF, Chan KH, Yuan S, To WK, Tsang DN, et al. Serum antibody profile of a patient with Coronavirus Disease 2019 reinfection. Clin Infect Dis. 2021;72(10):e659-62.

14. Van Elslande J, Vermeersch P, Vandervoort K, Wawina-Bokalanga T, Vanmechelen B, Wollants E, et al. Symptomatic SARS-CoV-2 reinfection by a phylogenetically distinct strain. Clin Infect Dis. 2021;73(2):354-6.

\section{Publisher's Note}

Springer Nature remains neutral with regard to jurisdictional claims in published maps and institutional affiliations.

Ready to submit your research? Choose BMC and benefit from:

- fast, convenient online submission

- thorough peer review by experienced researchers in your field

- rapid publication on acceptance

- support for research data, including large and complex data types

- gold Open Access which fosters wider collaboration and increased citations

- maximum visibility for your research: over $100 \mathrm{M}$ website views per year

At BMC, research is always in progress.

Learn more biomedcentral.com/submissions 